\title{
Assessment of Knowledge, Attitude and Practices Regarding Antenatal Care Among Urban and Rural Women of Tehsil Hajira District Poonch: A Comparative Study
}

\author{
Farah Tabassam $^{1}$, Tahira Amjad ${ }^{2}$, Attiya Hameed Khan ${ }^{1, ~ *, ~ S a d a f ~ J a m i l ~}{ }^{1}$ \\ ${ }^{1}$ Department of Public Health, Armed Forces Postgraduate Medical Institute, Affiliated with National University of Medical Sciences \\ (NUMS), Rawalpindi, Pakistan \\ ${ }^{2}$ Department of Community Medicine, Foundation University, Islamabad, Pakistan
}

\author{
Email address: \\ Farahkhan687@gmail.com (F. Tabbasam), tahiraamjad58@gmail.com (T. Amjad), Attiyahameed864@gmial.com (A. H. Khan), \\ sadafradiology@gmail.com (S. Jamil) \\ ${ }^{*}$ Corresponding author
}

\section{To cite this article:}

Farah Tabassam, Tahira Amjad, Attiya Hameed Khan, Sadaf Jamil. Assessment of Knowledge, Attitude and Practices Regarding Antenatal Care Among Urban and Rural Women of Tehsil Hajira District Poonch: A Comparative Study. Central African Journal of Public Health. Vol. 6, No. 5, 2020, pp. 237-241. doi: 10.11648/j.cajph.20200605.11

Received: July 5, 2020; Accepted: August 3, 2020; Published: August 25, 2020

\begin{abstract}
The objectives of my study was to assess the current Knowledge, Attitude and Practices of women belonging to reproductive age group of tehsil Hajira regarding antenatal care, to identify the barriers towards not seeking antenatal care, to compare the rural-urban antenatal care seeking behavior of these women and the services provided and to suggest viable recommendations in relation to creating awareness among rural and urban women regarding antenatal care. Descriptive cross sectional, comparative study, at Tehsil Hajira district Poonch AJK Pakistan. Data was collected through pre-structured questionnaire with both open and close ended questions given to respondents. Total of 400 sampled for the study (200 Urban and 200 rural women) questionnaires were completed, giving a response rate of $100 \%$. The mean age of Responded rural women was $35.58 \pm 6.549$ and urban women was $34.20 \pm 6.452$. Most of the rural women had good knowledge about ANC (70\%) others had bad knowledge (30\%), while the urban had knowledge (80\%). Attitude of rural women towards ANC was very low (38.43\%) while the urban women had also bad attitude towards ANC (31\%). The Mean score of ANC visits was $3.03 \pm 1.977$ for rural women while it was satisfactory for urban women, 3.89 2,491. A significant difference was seen between Rural and urban women about ANC. Antenatal care is an important implication of quality of life and overall public health. In Kashmir, there is a poor maternal and child health services due to many barriers especially among rural women. Most of the rural women goes towards local private hospitals for delivery but urban women goes towards local private and out of city for delivery during last pregnancy. There is a significant difference between rural and urban women towards ANC.
\end{abstract}

Keywords: Antenatal Care, Antenatal Services, Reproductive, Knowledge, Attitude, Practices, Delivery, Antenatal Visits

\section{Introduction}

Antenatal care (ANC) is the everyday healthcare of expected healthful pregnant women much less symptoms, orderly diagnose the diseases or complications related to obstetrics and to make contributions with admire to lifestyle, pregnancy, antenatal care and delivery [1]. World Health Organization (WHO) device the secure motherhood bundle in 1994 comprised 4 components; antenatal care, circle of relatives planning, safe delivery, and vital obstetric care [2].
Maternal health and health care are important determinants of neonatal survival and child fitness results. Therefore, improvements of maternal and child health are important global public fitness goals [3].

Seventy five percent of maternal deaths occurs in the course of childbirth and the postpartum period, and the extensive majority of those deaths are preventable. For Provision of professional take care of all women before, throughout, and after childbirth is a key method for saving women's lives and ensuring the first-rate practices of 
delivering a healthful child. ANC and transport care are taken into consideration fundamental components in any maternal healthcare application. Global estimates of Maternal Mortality Ratio (MMR) reduced with the aid of $48 \%$ at some stage in 1990-2010, from four hundred to 210 in line with one 100,000 live births. The annual decline charge changed into $3.1 \%$, simply over half that needed to obtain the MDG5 goal [4].

For Pakistan and all of the different nations, success of maximum of the goals of MDGs is based on Goal No. 2Achieving Universal Primary Education. Education is the important thing to fulfillment and we are able to reap all the goals, if right schooling is made reachable to each person. If we provide satisfactory training to our future generations, then many regions may be improvised finally. Following are the examples of countries, in which training advanced the conditions of all of the sectors. Education promotes gender equality (MDG Goal 3). It is due to presenting same possibility of schooling to males and females in Mali with secondary or better education have an average of 3 kids while an uneducated girls have a mean of 7 kids. Education reduces baby mortality (MDG Goal 4) [5].

Pakistan has the higher child birth rate of 21.9 births/1000 and Maternal mortality rate (MMR) is 178 deaths per 100,000 live births over 2015. During Antenatal care 20, 000 mothers' loss their lives every year. Most of females in the country rely of ANC on their relatives or untrained "Dais" for antenatal care. This care is mainly based on none scientific myths or observations/experience of the Antenatal care. Only a small fraction of females visit the professionals for proper antenatal care [6].

In Pakistan, ANC services mentioned any services provided via professional fitness personnel, consisting of medical doctors, midwives, lady health visitors (LHVs) and female medical experts (LHWs). We excluded the ones ANC services provided by non-fitness professionals such as traditional delivery attendants. A sensitivity analysis became additionally finished for babies whose mothers in no way attended any antenatal service for her remaining Antenatal care inside 5 years preceding every survey. Antenatal care is preventive strategy to deal with potential health problems during the course of Antenatal care. Pakistan has high birth rate, maternal mortality rates and particularly poor maternal health care indicators, level of awareness, literacy rate, maternal care and scarcity of specialized health care facilities are low in prevailing area. We were unable to achieve the MDGs which lead to maternal and child mortality and morbidity [7].

There is no study on ANC in Azad Jammu Kashmir (AJK) particularly in the rural and urban sphere of Tehsil Hajira. Our study may provide an overall situation of the knowledge, attitude and practices regarding ANC amongst women of rural, urban areas of tehsil Hajira district Poonch. This study results can help to recommend various interventions which can lead to improvement in maternal and child health. It will also contribute towards creating awareness among women belonging to rural and urban area of Tehsil Hajira. It will also seek the attention of respective authorities for provision of $\mathrm{ANC}$ in villages of this area as per WHO criteria.

\section{Material and Methods}

\subsection{Study Design}

The study was community based, comparative, cross sectional study conducted at rural and urban women of Tehsil Hajira District Poonch.

\subsection{Study Tool}

A pre structured questionnaire with the help of previous studies 1 was distributed to LHWs of respected area/sector. All the questions were properly explained to LHW's. The responses were plotted on the questionnaire. The researcher coded and entered the data into SPSS version 22 after obtaining the filled questionnaires from LHW's.

\subsection{Study Duration}

Study was conducted over a period of 6 months, from June 2018 to December 2018.

\subsection{Sample Size}

Calculated sample size was 400. That was divided into 200 Rural and 200 urban women.

\subsection{Sampling Methods}

To obviate bias, rural Sample was collected by using multistage probability sampling method. Tehsil Hajira consists of six union councils each having 9-13 villages. By simple random sampling union council Bhandari was selected as target which has 12 villages. From this union council every third village was selected by using systematic random sampling method. Villages selected were Narwal, Bari, Naryola and Bhango. By using non-probability convenient sampling 50 samples were selected from each village to meet the 200 sample. Urban Sample was collected by using multistage probability sampling method. Main Hajira city consists of 4 market area's each having 100-150 households. By simple random sampling two market areas were selected. Selected market areas were College chowk Market and Thana Road market Pull Bazar. By using non- probability convenient sampling 100 samples were selected from each market areas to meet the 200 sample.

\subsection{Data Analysis}

Data was entered into Statistical Package for Social Sciences (SPSS) model 25 for analysis. Responses were coded as 1 for sure and zero for NO, and most of questions on 5 factor Likert scale had been coded with 1 for Strongly agree, 2 for agree, 3 for neutral, 4 for strongly disagree and five for disagree even as those ratings were taken as mixed score all through interpretation as strongly agree and agree combine different hand neutral, strongly disagree, disagree in 
combined score. Each item of the questionnaires was taken as a variable and analyzed for the responses.

To find the association between barriers towards not seeking antenatal and KAP linear logistic model was used for both rural and urban data. To analyze the comparisons between knowledge, attitude and practices, Spearman's chisquare was also applied for the comparison among rural and urban women of tehsil Hajira. To find the association between all the variables was calculated by spearman's chisquare while linear regression model was carried between the barriers towards not seeking ANC and KAP for multi-variate analysis. For rural and urban comparison T-test was used between the KAP.

\subsection{Ethical Consideration}

The study was conducted after obtaining approval from Institutional review board of AFPGMI (Armed Forces Postgraduate Medical Institute). Consent was also taken from the ethical review committee of rural and urban areas of tehsil Hajira. Written informed consent was taken from all the women participating in the study.

\section{Results}

Table 1. Mean score of knowledge attitude and practices regarding antenatal care.

\begin{tabular}{lll}
\hline & Rural $\mathbf{N}=\mathbf{2 0 0}$ & Urban $\mathbf{N}=\mathbf{2 0 0}$ \\
\hline Knowledge & 71 & 81 \\
Knowledge & 46 & 32 \\
Practices & 71 & 73 \\
\hline
\end{tabular}

Table 1 shows the mean score of knowledge (Rural) 71, knowledge (urban) 81, attitude (rural) 46, and attitude (urban) 32 and practices (rural) 71 and practices (urban) 73.

Table 2 shows the results where knowledge regarding antenatal care among urban women and rural women was assessed for association with attitudes regarding antenatal care among urban and rural women by applying chi square. The results suggest that there is no significant relationship between knowledge (urban) and knowledge (rural) with attitude (urban) and attitude (rural) as the values of chi square indicates.

Table 2. Association of rural, urban knowledge and Attitude towards ANC.

\begin{tabular}{lll}
\hline \multirow{2}{*}{ Variables } & Attitude & \\
\cline { 2 - 3 } & Rural $\mathbf{N}=\mathbf{2 0 0}$ & Urban $\mathbf{N}=\mathbf{2 0 0}$ \\
\hline Knowledge Rural & $210(\mathrm{df}=84, \mathrm{p}=.00)$ & $60.87(\mathrm{df}=72, \mathrm{p}=.82)$ \\
Knowledge Urban & $54.12(\mathrm{df}=48, \mathrm{p}=.25)$ & $57.86(\mathrm{df}=56, \mathrm{p}=0.40$ \\
\hline
\end{tabular}

Table 2 shows the results where knowledge regarding ANC among urban women and rural women was assessed for association with attitudes regarding ANC among urban and rural women by applying chi square. The results suggest that there is no significant relationship between knowledge (urban) and knowledge (rural) with attitude (urban) and attitude (rural) as the values of chi square indicates.

Table 3. Association of rural, urban Attitude with practices towards ANC.

\begin{tabular}{lll}
\hline \multirow{2}{*}{ Variables } & Practices & \\
\cline { 2 - 3 } & Rural $\mathbf{N}=\mathbf{2 0 0}$ & Urban $\mathbf{N}=\mathbf{2 0 0}$ \\
\hline Attitude Rural & $138.31(\mathrm{df}=119, \mathrm{p}=.10)$ & $60.87(\mathrm{df}=72, \mathrm{p}=.82)$ \\
Attitude Urban & $99.68(\mathrm{df}=90, \mathrm{p}=.22)$ & $57.86(\mathrm{df}=56, \mathrm{p}=0.40)$ \\
\hline
\end{tabular}

Table 3 shows the results where attitudes regarding ANC among urban women and rural women was assessed for association with practices regarding ANC among urban and rural women by applying chi square. The results suggest that there is no significant relationship between attitude (rural) and attitude (urban) with practices (rural) and practices (urban) as the values of chi square indicates.

Table 4. Association of rural urban Knowledge and practices towards ANC.

\begin{tabular}{lll}
\hline \multirow{2}{*}{ Variables } & Practices & \\
\cline { 2 - 3 } & Rural $\mathbf{N}=\mathbf{2 0 0}$ & Urban $\mathbf{N}=\mathbf{2 0 0}$ \\
\hline Knowledge rural & $162.58(\mathrm{df}=136, \mathrm{p}=.06)$ & $60.87(\mathrm{df}=72, \mathrm{p}=.82)$ \\
Knowledge Urban & $197.9(\mathrm{df}=204, \mathrm{p}=.60)$ & $57.86(\mathrm{df}=56, \mathrm{p}=0.40$ \\
\hline
\end{tabular}

Table 4 shows the results where knowledge regarding ANC among urban women and rural women was assessed for association with practices regarding ANC among urban and rural women by applying chi square. The results suggest that there is no significant relationship between knowledge (rural) and knowledge (urban) with practices (rural) and practices (urban) as the values of chi square indicates.

Table 5. Comparison of Knowledge regarding ANC in Urban women with Knowledge inRural women, Attitude regarding ANC in Urban women with Attitude in Rural women and practices regarding ANC in Urban women with practices in Rural women $(n=400)$.

\begin{tabular}{|c|c|c|c|c|c|c|c|}
\hline \multirow{2}{*}{ Scales } & \multirow{2}{*}{$\begin{array}{l}\text { Urban } \mathrm{N}=200 \\
\operatorname{Mean} \pm \text { SD }\end{array}$} & \multirow{2}{*}{$\begin{array}{l}\text { Rural } \mathbf{N}=\mathbf{2 0 0} \\
\text { Mean } \pm \text { SD }\end{array}$} & \multicolumn{5}{|c|}{ Results of t-Test (95\% CI) } \\
\hline & & & $\mathbf{t}$ & df & $\mathbf{P}$ & $\mathbf{L L}$ & $\mathbf{U L}$ \\
\hline Knowledge & $10.54 \pm 1.8$ & $8.86 \pm 2.1$ & 57.0 & 199 & .00 & 8.55 & 9.17 \\
\hline Attitude & $14 \pm 1.4$ & $12.58 \pm 1.9$ & 89.5 & 199 & .00 & 12.30 & 12.86 \\
\hline Practices & $9.77 \pm 3.0$ & $12.37 \pm 6.0$ & 28.7 & 199 & .00 & 11.52 & 13.22 \\
\hline
\end{tabular}

Table 5 show the results of t-test for comparing mean differences on Knowledge regarding ANC in Urban women with Knowledge regarding ANC in Rural women, Practices regarding ANC in Urban women with Practices regarding ANC in Rural women and Attitude regarding ANC in Urban women with Attitude regarding ANC in Rural women. It is clear that differences are significant among urban and rural women for all variables. Thus indicating that knowledge regarding ANC in urban women $(10.54 \pm 1.8)$ is greater than knowledge in rural women $(8.86 \pm 2.1)$. On the other hand, practices regarding ANC in urban women (9.77 \pm 3.0 ) is lower than rural women $(12.37 \pm 6.0)$. Whereas, attitude regarding ANC in urban women $(14 \pm 1.4)$ is greater than rural women (12.58 \pm 1.9$)$. 


\section{Discussions}

As increasing female literacy over the past few years in Pakistan, a very higher number of the women in our study showed good knowledge about ANC among urban and rural setting but we cannot forget about the score about bad knowledge $63(31.5 \%)$. Maternal mortality ratio of Pakistan is 178 per 100,000 live births annually which translates into about 15,000 deaths each year or 40 deaths every day due to Antenatal care and child birth related causes [8]). A study done in rural Jhang, Pakistan Parity and education had the largest impact on institutional delivery: women were substantially less likely to deliver at a health facility after their first birth; women with primary or higher education were much more likely to have an institutional delivery. Age, autonomy, household wealth, proximity to a health facility and exposure to mass media were also important drivers of institutional delivery. The use of family planning within a year of delivery was low, with parity, education and husband's approval being the strongest determinants of use famil planning methods [9].

The results of this study showed that 108 (54\%) of women belonging to rural area have bad attitude towards ANC while 77 (38.47\%) of women shows good attitude towards ANC and $68 \%$ from urban area have bad attitude but most of urban women agreed towards hospital delivery by proficient birth attendants A similar survey conducted in South West Ethiopia, found that almost $70.6 \%$ of the respondents desired to follow ANC and other $29.4 \%$ of women do not need to follow ANC if they become pregnant due to negative attitude [10]. This was also because of the belief that the women living in rural areas of tehsil Hajira have knowledge about ANC but they have very poor attitude about ANC due to many barriers for not seeking ANC.

In our study score for the number of ante-natal visits during last antenatal care was $3.03+1.977$ because most of women have barriers towards not seeking ANC. While mean number of antenatal visits for urban women was 3.89+2.491 which is better than rural because rural women have very fewer barriers like transport and availability of THQ hospital in city Hajira and many private hospitals and clinics. In a survey 9 out of 10 women in a rural area reported one ANC visit during their last Antenatal care however two-thirds of the women go into attending the ANC in third trimester, and only halved of these women proceed the recommended figure of 4 ANC visits [11].

Women during last delivery most of women deliver their babies in hospital $76 \%$ while $23 \%$ women gave birth at home. Women who delivered in hospitals $47 \%$ of women goes towards local private hospital and many others goes out of city like CMH Rawlakot, DHQ Kotli and PIMS Islamabad. In case of urban data our study revealed that mostly women goes to hospital during last delivery very fewer delivered at home. Most of them goes to local private hospital for delivery while others goes towards government hospital and out of city. This might be due to service provision and barriers for rural women and urban women have accessibility to health services. A survey conducted in a rural area in Islamabad 390 women of 1549 years of aged women were asked about ANC. Out of 390 women $87.4 \%$ had the knowledge of services and their importance, a total of 53.3\% women availed ANC and the number of those delivering at health facility less than $40.5 \%$ and at home raised to $32.1 \%$ [12].

A similar study in rural women also received ANC from private health facilities more often than the urban women. The high proportion of rural women who received ANC from the local sector, with higher expenses per visit than in government sector, although availing more ANC from the local sector, the rural women consumed less money for ANC than urban women. It might be assumed by the lower number of visits, and the ordinary services they had course of ANC visits. The raised proportion of women who availed ANC at private health resources can possibly justify the poor adequacy of ANC in the rural sector while the obedience with national guidelines in the private health sector is still unclear [13].

The results of our study shows t-test for comparing mean differences on knowledge towards ANC in urban with Knowledge regarding ANC in Rural, Practices towards ANC in Urban women with Practices regarding ANC in Rural women and Attitude regarding ANC in Urban women with Attitude regarding ANC in Rural women. It is clear that differences are significant among urban and rural women for all variables. Thus indicating that knowledge regarding ANC in urban women $(\mathrm{M}=10.54$ $\mathrm{SD}=1.8)$ is greater than knowledge in rural women $(\mathrm{M}=8.86, \mathrm{SD}=2.1)$. On the other hand, practices regarding ANC in urban women $(\mathrm{M}=9.77, \mathrm{SD}=3.0)$ is lower than rural women $(\mathrm{M}=12.37, \mathrm{SD}=6.0)$. Whereas, attitude regarding $\mathrm{ANC}$ in urban women $(\mathrm{M}=14.0, \mathrm{SD}=1.4)$ is greater than rural women $(\mathrm{M}=12.58, \mathrm{SD}=1.9)$. In a study of ANC capability in rural and urban settings people living in the rural area was significantly linked with lower suitable use of ANC compared to existing in the urban area, both regarding quantity and content. Low education, living in poor households and exclusively using private sided ANC in both sites and self-employment, be pregnant before 25 years of age and existing in poor communities in the rural area bend to increase the risk for mostly inadequate ANC. Risk containing pregnancy could not be experienced to be associated with ANC fairness in either site [14].

\section{Conclusion}

In conclusion knowledge towards antenatal care among rural and urban women was agreeable because the source of information regarding antenatal care was Lady Health Workers. The attitude of rural and urban women was not proper due to many barriers, but the practices were good among rural and urban women. Most of the rural women go towards local private hospitals for delivery but urban women goes towards local private and out of city for delivery during 
last Antenatal care. Most of women had not go for perinatal care due to family/husbands constraints and barriers. There in a significant difference between rural and urban women towards. Maternal health services are not improved in rural and urban areas of tehsil Hajira.

\section{Acknowledgements}

I pay my gratitude to my beloved family, teachers and friends whose continuous support, prayers and sacrifices remained a source of inspiration throughout completion of my study.

\section{References}

[1] Iiyambo N. 2017 Barriers to utilization of antenatal care services among pregnant women in Omaheke region, Namibia (Doctoral dissertation).

[2] Arya, A., Mehra, N. and Mehra, J. S., 2017. To study the knowledge, attitude and practices regarding Antenatal Care among Pregnant women in Haldwani Block, District Naintal (Uttarakhand). J Med SciClin Res.

[3] Van Eijk, A. M., Bles, H. M., Odhiambo, F., Ayisi, J. G., Blokland, I. E., Rosen, D. H., Adazu, K., Slutsker, L. and Lindblade, K. A., 2012. Use of antenatal services and delivery care among women in rural western Kenya: a community based survey. Reproductive health.

[4] World Health Organization, Unicef. Trends in maternal mortality: 1990 to 2013: estimates by WHO, UNICEF, UNFPA, The World Bank and the United Nations Population Division: executive summary. World Health Organization; 2014.

[5] Griggs D, Stafford-Smith M, Gaffney O, Rockström J, Öhman
MC, Shyamsundar P, Steffen W, Glaser G, Kanie N, Noble I. Policy: Sustainable development goals for people and planet. Nature. 2015 Mar.

[6] Biermann F, Kanie N, Kim RE. Global governance by goalsetting: the novel approach of the UN Sustainable Development Goals. Current Opinion in Environmental Sustainability. 2017 Jun.

[7] Carroli G, Rooney C, Villar J. How effective is antenatal care in preventing maternal mortality and serious morbidity. Reproduction and contraception. 2015.

[8] Gatrell AC, Elliott SJ. Geographies of health: An introduction. John Wiley \& Sons; 2014 Dec 31.

[9] Agha S, Carton TW. Determinants of institutional delivery in rural Jhang, Pakistan. International journal for equity in health. 2011 Dec.

[10] Henok A, Getachew HW, Workiye H. Knowledge, Attitude and Practice of Antenatal Care Service among Married Women of Reproductive Age Group in Mizan Health Center, South West Ethiopia. J Med Physiol Biophys. 2015.

[11] Knudsen LM. Reproductive Rights in a Global Context: South Africa, Uganda, Peru, Denmark, United States, Vietnam, Jordan. Vanderbilt University Press; 2016.

[12] Sadiq N, Waheed Q, Hussain M, Rana AT, Chaudry ZYZ, Salman $S$ et al. Factors affecting the utilization of antenatal care among women of reproductive age in Nurpur Shahan. J Pak Med Assoc. 2014.

[13] Duflo E. Women empowerment and economic development. Journal of Economic literature. 2016 Dec.

[14] Tran TK, Gottvall K, Nguyen HD, Ascher H, Petzold M. Factors associated with antenatal care adequacy in rural and urban contexts-results from two health and demographic surveillance sites in Vietnam. BMC health services research. 2012 Dec. 